\title{
LAS LEYES DE DROGAS EN BRASIL Y SU RELACIÓN EN LA PRODUCCIÓN DE POLÍTICAS DE IDENTIDAD: UN ANÁLISIS DE LOS PROCESOS DE ESTIGMATIZACIÓN Y PROMOCIÓN DE LA ALTERIDAD, DESDE LA PERSPECTIVA DE LA PSICOLOGÍA SOCIAL CRÍTICA'
}

\author{
THE DRUG LAWS IN BRAZIL AND THE PRODUCTION OF POLITICS OF IDENTITY: \\ PROCESSES OF STIGMATIZATION AND PROMOTION OF ALTERITY FROM THE \\ PERSPECTIVE OF CRITICAL SOCIAL PSYCHOLOGY
}

Recibido: 28 de Febrero del 2011 | Aceptado: 14 de Julio del 2011

ALUÍSIO FERREIRA DE LIMA ${ }_{2}$; JOSÉ UMBELINO GONÇALVES NETO ${ }_{3} ;$ MEIRE SILVA DE LIMA ${ }_{4}$ (UNIVERSIDAD FEDERAL DO (EARÁ, Brasil).

\begin{abstract}
RESUMEN
Este artículo tiene como objetivo presentar un análisis, en la perspectiva de la psicología social crítica, de las leyes de drogas en Brasil y su relación con la producción de las políticas de identidad que producen estigmatización o la promoción de la alteridad. (on este fin, presentaremos l) el desarrollo de las leyes de drogas y su relación con las políticas de reglamentación de la venta y la represión del consumo, 2) los avances y retrocesos a lo largo del siglo XX en Brasil de las leyes de drogas, especialmente la separación entre adicto y traficante de drogas, y la relación posterior con el Estado, derecho y medicina, 3) las transformaciones de la política de la identidad dirigida a los consumidores de drogas, sobre todo después de los años de 80 y de la aplicación de la Política y Estratégia de Reducción del Daños (RD). El artículo permitirá a la comprensión tanto de los marcos jurídicos que ayudan a crear y justificar en el espacio publico las estratégias de regulación de drogas en Brasil y la aplicación de políticas de identidad estigmatizadoras dirigidas a los usuarios de drogas, como tambiém presentará los posibles avances en la aplicación de la políitica de reducción de daños.
\end{abstract}

PALABRAS CLAVE: Psicología social; leyes de drogas; política de identidad, reducción de daños.

\section{ABSTRACT}

This article aims to present an analysis, in Critical Social Psychology perspective, about the drug laws published in Brazil and its relation to the production of stigmatizing politics of identity and the promotion of alterity. For this purpose, will be presented 1) the development of drug laws and their relationship with the regulatory policies of the sale of drugs and repression of use, 2) the advances and setbacks of drug laws along the twentieth century, especially the separation of the characters: addicted and drug dealer and the subsequent relationship between state, law and medicine, 3) the transformations of politics of identity directed at drug users, especially after the years of 1980 and the implementation of the Policy and Strategy for Harm Reduction. The article will enable the understanding of the legal frameworks that helped to create and justify in Brazilian public sphere the drug enforcement strategies and stigmatizing politics of identity directed to drug users. It will reveal the achieved advances with the implementation of the Harm Reduction policy.

KEY WORDS: Social psychology, drug laws, politics of identity, harm reduction

\footnotetext{
1. Agradecemos à Fundação Cearense de Apoio ao Desenvolvimento Científico (FUNCAP) pelas bolsas de produtividade, iniciação científica e apoio técnico.

2. Psicólogo com Pós-Doutorado, Doutorado e Mestrado em Psicologia Social pela Pontifícia Universidade Católica de São Paulo (PUCSP) e Especialista em Saúde Mental pela Escola de Enfermagem da Universidade de São Paulo (EEUSP). Professor Adjunto do Setor de Psicologia Social do Curso de Psicologia e do Programa de Pós-Graduação em Psicologia da Universidade Federal do (eará (UFC). Bolsista de Produtividade em Pesquisa FUNCAP. Email: aluisiolima@hotmail.com

3. Graduado em Letras (Português e Literaturas Vernáculas) pela Universidade Federal do Ceará (UFC) e ałua Imente graduando em Psicologia nessa mesma universidade. Bolsista de iniciação científica FUNCAP. Email: jugneto@gmail.com

4. Graduada em Ciências Sociais pelo Centro Universitário Fundação Santo André. Bolsista de Apoio Técnico pela FUNCAP na Universidade Federal do Ceará (UFC). Email: meirecientistasocial@hotmail.com.
} 
Considerações iniciais sobre um campo complexo e uma moral vacilante

O uso, abuso e dependência de drogas não é um fenômeno moderno, diversos autores já evidenciaram que é possível encontrar relatos sobre o uso de drogas desde os primórdios da história da humanidade (Escohotado, 1997; Lima, 2005; MacRae, 2008; Velho, 1997). Contrariando discursos retóricos que proclamam a utopia da "sociedade sem drogas", esses estudos ensinam que nunca existiu (e possivelmente nunca existirá) uma sociedade sem drogas. Isso porque o uso de substâncias sempre esteve relacionado com rituais de transcendência do espírito, formas de tratamento e diminuição dos males do corpo e da subjetividade, celebrações e festejos entre familiares e amigos, aumento do rendimento da força de trabalho, etc.

Se observarmos de forma crítica como tem sido feito 0 uso de drogas na contemporaneidade, veremos que o mesmo não mudou muito desde os primeiros relatos de experiências com essas substâncias. Podemos inferir que o que mudou em nossa sociedade é a forma como os indivíduos, socializados sob o discurso do consumo irrefreado, têm se relacionado com essas substâncias e a forma como são reconhecidos e se reconhecem os indivíduos que fazem uso de determinados tipos de droga, em um mundo ao mesmo tempo igualitário e desigual: "igualitário nas ideias e costumes que impõe, e desigual nas oportunidades que oferece" (Galeano, 2010, p. 25).

O uso de drogas na contemporaneidade mostra-se um "mal" necessário para a organização pessoal e social; seja no cafezinho antes do trabalho, na cerveja do final de semana, nos medicamentos para dormir, para engordar ou para emagrecer, nas drogas utilizadas nas danceterias, nas escolas etc., seja para a integração de grupos, seja para ter alto rendimento, ou ainda, para fugir da realidade massacrante na qual 0 indivíduo está inserido. Onde mesmo a questão da legalidade/ilegalidade dessas substâncias, como assinala Lima (2005, p. 240), está ligada não à letalidade e potencial de dependência de determinada droga, mas a uma moral vacilante "que em um determinado momento faz com que sejam incentivadas, liberadas, legalizadas etc., e noutro proibidas, por serem consideradas perniciosas, (...) financiam exércitos, compram e vendem armamentos, geram empregos, patrocinam políticos e sustentam a existência de diversas organizções".

Também é possível dizer que não existe uma causa objetiva, uma ou mais variáveis com as quais se poderia relacionar 0 fenômeno do uso de drogas, pois este fenômeno está relacionado a aspectos de ordem subjetiva e singular a cada indivíduo, ao mesmo tempo, o uso de drogas também é incentivado pela grande indústria cultural e pelas complexidades vividas no mundo concreto. Há consumidores de drogas em todas as classes sociais; 0 que os diferencia, eventualmente, são a qualidade e os tipos de drogas consumidos, em decorrência das capacidades aquisitivas e das distinções sociais. Tal como no exemplo de Galeano (2010, p.13), "muito antes de que as crianças ricas deixem de ser crianças e descubram as drogas caras que assustam a sociedade e desmascaram 0 medo, as crianças pobres estão aspirando gasolina ou cola de sapateiro".

Como podemos observar, a relação que estabelecemos com as drogas é complexa. De um lado, elas são utilizadas pelos indivíduos como combustível e veículo, fonte de energia para a ação, voltadas para o lúdico, para a representação da identidade e do grupo a que se pertence; também servem para o necessário devaneio, para a leveza da alma que precisa flutuar e transgredir limites impostos pela ordem sistêmica que tornam a realidade insuportável. Por outro lado, também são as mercadorias inseridas na lógica capitalista: são usadas, consumidas, para marcar 
diferenças sociais e, assim transmitir mensagens, que reforçam e validam políticas de identidade estigmatizadoras que se tornam regras normativas de conduta que muitas vezes impedem que os indivíduos consigam sua diferenciação e, "aparece na orientação feita ao estigmatizado no sentido de que se ele adotar uma linha correta ele terá boas relações consigo e será um homem completo, um adulto com dignidade e autorespeito" (Goffman, 1988, p. 134).

A própria política de repressão às drogas, exclusivamente que se propõe a livrar a sociedade do narcotráfico, ao tratar os usuários de drogas como principais responsáveis por suas mazelas, acabam fortalecendo a precariedade e a clandestinidade que tanto vulnerabilizam os indivíduos. Ou seja, ao invés de desestimular o uso da droga, "reforça-o por meio do rebaixamento contínuo da autoestima desses indivíduos, negando-lhes 0 acolhimento e a aceitação social, estimulando-os a integrar-se com outros indivíduos marginalizados por diferentes desvios e/ou estigmas" (Amaral, 2000, p.46).

Esse fenômeno ocorre pelo fato de que determinadas políticas de identidade configuram de forma direta determinadas identidades coletivas. Assim, tais políticas identitárias acabam por expressar um tipo de discurso a favor de uma autodeterminação excludente, "o que significa que dentro de tais políticas 0 indivíduo acaba por se colocar diante do outro de forma estigmatizada a partir da representação, consciente ou não, de uma determinada personagem" de sua identidade (Lima, 2010a, p. 170).

Esses breves apontamentos são importantes porque permitem questionar 0 reducionismo apresentado por uma determinada produção de conhecimento centrada num paradigma que tradicionalmente prezava a observação, a experimentação e a quantificação dos aspectos materiais da realidade, cujo pensamento sobre as drogas psicoativas centrou-se apenas nos efeitos químicos das substâncias no corpo, ignorando os fatores históricos, sociais, culturais e psicológicos relacionados ao uso. Tal paradigma apoiou e direcionou políticas públicas e leis que, ao não diferenciarem os contextos psicossociais em que se inserem aqueles que fazem o uso de drogas, acabaram por considerar como necessariamente patológico e gerador de dependência todo e qualquer tipo de utilização que estivesse fora da norma estabelecida, assim como transformou os usuários em doentes ou criminosos.

Tendo em vista que a compreensão dos aspectos históricos presentes na constituição dos sujeitos é essencial para um posicionamento crítico frente ao fenômeno do uso de drogas na contemporaneidade, nos parece interessante observar como se deu, através da história, essa constituição de um sujeito, o qual, como assinala Foucault (2009, p. 10), "não é dado definitivamente, que não é aquilo a partir do que a verdade se dá na história, mas de um sujeito que se constitui no interior mesmo da história, e que é a cada instante fundado e refundado pela história".

Para tanto, parece-nos imprescindível compreender 1) o desenvolvimento das leis de drogas e sua relação com as políticas de regulação da venda e repressão do uso; 2) os avanços e retrocessos ao longo do século XX das leis de drogas, sobretudo a separação das personagens: viciado e traficante e a subsequente articulação entre Estado, Direito e Medicina; 3) discutiremos as transformações das políticas de identidade direcionadas aos usuários de drogas, sobretudo após os anos de 1980 e a implementação da Política e Estratégia de Redução de Danos; e, 4) apresentaremos algumas breves reflexões sobre o papel dos psicólogos nesse processo. $O$ entendimento 
dessas proposições normativas oferece elementos que podem esclarecer a construção de políticas de identidade estigmatizadoras para os usuários de drogas, ou ainda, oferecer políticas de identidade com potencial emancipatório.

As leis de drogas no Brasil e a produção de políticas de identidade estigmatizadoras

No Brasil a carta magna que institui a Constituição de 1824, assinada pelo então Imperador Dom Pedro Primeiro, já previa no seu artigo $8^{\circ}$, a suspensão dos direitos políticos por incapacidade "physica, ou moral" (Brasil, 1824). Entretanto, não discutia em nenhum de seus artigos a questão do uso de drogas pelos indivíduos. De fato, o Regulamento Imperial, Decreto $n$. 828 de 1851, será a primeira lei a materializar a preocupação do Estado com as substâncias psicoativas, ao criar a polícia sanitária e disciplinar a venda de remédios (Brasil, 1851).

O Regulamento Imperial dará início à criação de leis e decretos que, como veremos adiante, terão como objetivo a administração da ordem social e a separação das figuras do usuário de drogas e do narcotraficante. Em seguida, após os tempos do Imperador D. Pedro II, "o Código Penal de 1890, o primeiro da República, considerava crime contra a saúde pública 'expor à venda, ou ministrar, substâncias venenosas, sem legítima autorização e sem as formalidades previstas nos regulamentos sanitários"' (Gonzaga, 1963, p. 25 como citado em Rodrigues, 2004, p. 27). Adentrando o século $X X$, no início da primeira década, promulgou-se no estado de São Paulo o Decreto Estadual n. 2.141, de 14 de novembro de 1911 (São Paulo, 1911). Segundo Rodrigues, este decreto foi instituído como uma variação estadual do Código Penal de 1890 e previa a fiscalização vigorosa de farmácias e hospitais "a fim de limitar os desvios de drogas controladas para o mercado negro. (...) criava a Polícia Sanitária, organização que instrumentalizava ações de gestão social ao vigiar farmácias, panificadoras, restaurantes e bares, autuando irregularidades" (Rodrigues, 2004, p. 132).

Em um período onde já se priorizava no país a maximização da capacidade produtiva e da força de trabalho, buscando o enfraquecimento da capacidade política dos trabalhadores, que tinham suas movimentações vistas como "caso de polícia" pelo Estado, e a institucionalização do saber médico a partir da promulgação dos códigos sanitários, os médicos se tornam os únicos autorizados a regulamentar a venda de drogas e promover as políticas de saúde. A economia brasileira, impulsionada pela produção de um estimulante (café), desenvolvia na região Sudeste do país, principalmente em São Paulo, um pólo de desenvolvimento dinâmico e cosmopolita. Os cidadãos, por sua vez, não tardaram em importar os "hábitos sofisticados" dos europeus, tanto na moda como no comportamento social. 0 uso de éter, lança-perfumes, ópio e cocaína, ficava restrito a alguns círculos de intelectuais, médicos, dentistas, farmacêuticos (que lidavam diretamente com tais substâncias) e prostitutas, que frequentavam espaços sociais como 0 Teatro Municipal de São Paulo, inaugurado em 1911, sem maiores impactos sociais (Rodrigues, 2004).

Aliás, a expectativa era que a utilização de drogas controladas no Brasil se restringisse apenas aos prostíbulos finos e às fumeries sofisticadas, ou seja, fossem acessiveis apenas à burguesia. Entretanto, o controle da distribuição tornou a venda de drogas controladas um negócio clandestino extremamente lucrativo. Como assinala Rodrigues (2004, p. 130), a venda livre de drogas psicoativas é proibida, mas 0 acesso pelo receituário médico se transforma em via fácil para obtenção das drogas desejadas. 
A partir do fim da Primeira Guerra em 1918, o saber psiquiátrico, que veio se consolidando no fim do século XIX e início do XX no Brasil, começa a ganhar espaço nos discursos proibicionistas como argumento científico. As campanhas lançadas pelos jornais passam a destacar 0 uso de droga "(...) não mais como mero acessório exótico em casos policiais, mas como indutores de condutas psicopatológicas. Usuários são vistos agora como 'degenerados morais' e 'sociopatas em potencial'” (Rodrigues, 2004, p. 133).

A chamada medicina social começa a ditar os parâmetros de normalidade, criando a linha tênue que separa 0 indivíduo saudável do doente, do que é correto e 0 que é desviante. Assumindo como estratégia de prevenção a perseguição, eliminação e/ou confinamento do inimigo social interno (em geral os pobres, os criminosos, os desviados e os anormais), a medicina social passa a determinar e promover uma política de identidade estigmatizante, que além de reduzir os indivíduos que faziam uso das substâncias à condição de "degenerados" também os responsabilizava pela persistência dos problemas sociais (Lima, 2010a; Foucault, 1999). Isso o que rapidamente também justificará e reforçará a necessidade de criação de instituições para controlá-los e eventualmente "tratá-los", na perspectiva do tratamento moral pineliano, que "passou a ser utilizado como intervenção científica para o controle e a correção dos indivíduos não convencionais, repetindo a história dos países europeus e dos Estados Unidos" (Lima, 2010b, p.167). Tal política será fortalecida em 1923, com a publicação de dois decretos que considerarão de utilidade pública a Liga Nacional Contra 0 Alcoolismo, Decreto n. 4.665 (Brasil, 1923a) e a Liga Brasileira de Higiene Mental, Decreto n. 4.778 (Brasil, 1923b).

A prática do exame médico que identificava e separava os "doentes" dos "sadios" passa também a indicar tratamentos que serão transformados pelo poder governamental como estratégia de administração e controle da população. Sendo utilizado como estratégia biopolítica de governo dos corpos, como diria Foucault, o saber médico passa a valer-se de um poderoso vocabulário que legitima a racionalidade de suas técnicas e formas de intervenção.

Como era de se esperar, a prática do exame médico não significou uma superação do saber jurídico, muito pelo contrário. De fato, ocorreu o fortalecimento do acordo entre juristas, médicos e Estado, que se evidenciava da seguinte forma: os médicos passam a ter o monopólio para lidar com as substâncias controladas e 0 Estado, articulado com o judiciário conquista dois espaços de intervenção social muito importantes: um sobre o mercado legal; outro sobre o mercado ilegal (Rodrigues, 2004). O campo jurídico, sempre um importante aliado do Estado, proporcionava a capacidade ampliada de governabilidade das condutas individuais, "fornecendo instrumentos jurídicos para a vigilância do mercado legalizado pela lei (o de uso médico) e o ilegalizado por ela (o de uso lúdico)" (Rodrigues, 2004, p. 131). Ao mesmo tempo, legitimava os diagnósticos médicos e facilitava sua institucionalização, organizava e normatizava 0 uso das substâncias e implementava as punições para os que não seguissem a lógica instituída, uma vez que a responsabilidade pelo uso e dependência dos usuários era de ordem pessoal.

Essa quase indissociabilidade entre Estado, direito (justiça) e medicina ficará melhor evidenciada nos anos que se seguiram, quando foram aperfeiçoados os dispositivos de controle e a criação de medidas penais mais rígidas com o Decreto n. 4.294, de 6 de julho de 1921, inspirado na Convenção de Haia de 1921, tendo sido modificado pelo Decreto n. 15.683, seguindo-se regulamento aprovado pelo Decreto n. 14.969, de 3 de setembro de 
1921. O decreto n. 14.969 de 3 de setembro de 1921, mesmo com modificações ao longo desse ano, basicamente servirá para estabelecer as penalidades e diretrizes de tratamento. Mas o que chama a atenção nesse decreto é que a noção de tratamento é totalmente confundida com a ideia de penalidade, noção que até hoje em dia temos dificuldade de superar. 0 artigo $3^{\circ}$ deixa evidente 0 espírito higienista ao dizer que "embriagar-se por habito, de tal modo que por actos inequivocos se torne nocivo ou perigoso a Si proprio, a outrem, ou á ordem publica [resulta em pena de] internação por tres mezes a um anno em estabelecimento correccional adequado" (Brasil, 1921).

A associação entre criminalidade, ordem pública e tratamento médico nesse período é estreita, todas as intervenções parecem ser unicamente a representação das várias faces de um mesmo bloco de prescrições cuja finalidade última é a intervenção higienista sobre a sociedade. A divisão jurídica que deveria produzir duas políticas de identidade distintas produz a partir de então a identidade do "toxicômano" ou "psicopata toxicômano", que se tornará a política de identidade estigmatizante que justificará a vinculação dos usuários à medicina e à justiça.

Em 3 de julho de 1934 é publicado o Decreto n. 24.559 (Brasil, 1934), uma das primeiras leis de saúde mental do país. Este decreto, consolidando o poder psiquiátrico e a medicina social, institucionalizará a internação fechada dos "psicopatas" em estabelecimentos psiquiátricos (Brasil, 1934, Art. $\left.3^{\circ}, \S 1^{\circ}\right)$, estendendo tal internação aos ditos "toxicômanos": Art. $3^{\circ}, \S 5^{\circ}$ - "Podem ser admitidos nos estabelecimentos psiquiátricos os toxicômanos e os intoxicados por substâncias de ação analgésica ou entorpecente por bebidas inebriantes, particularmente as alcoólicas.". Assim, o decreto define que "A internação de psicopatas toxicômanos e intoxicados habituais em estabelecimentos psiquiátricos, públicos ou particulares, será feita" por ordem judicial ou a pedido de terceiros (Brasil, 1934, Art. 11).

O projeto de acolhimento da vítima nos sanatórios para toxicômanos, que passava a imagem de um Estado cuidador, protetor do cidadão, é contradita pelo aumento da repressão absoluta às drogas e aos usuários: concretamente 0 usuário é marginalizado, passando a fazer parte do submundo. $E$, por isso, se o usuário de drogas não é criminalizado na teoria, o é na prática, se não é encarcerado pela lei, é pelas relações sociais, se na lei a ação policial não incide sobre ele, na rua essa ação incide no peso do cassetete. Ainda assim, "saindo" a ação policial, a ação médica a substitui no encarceramento dos sanatórios, e no lugar de porretes, agulhas, no de algemas, camisas de força.

Outro marco jurídico importante foi a promulgação do Decreto-Lei n. 891, de 25 de novembro de 1938 (Brasil, 1938), o qual, estando de acordo com as determinações internacionais, lança a base da repressão às drogas psicoativas no Brasil. 0 Estado, subsidiado por mais aparelhos de controle a Comissão Permanente de Fiscalização de Entorpecentes (Brasil, 1936). Nesse período é retomada uma antiga política de identidade presente na carta magna de 1824, assinada pelo então Imperador Dom Pedro I e que não estava relacionada diretamente aos usuários de drogas, ou seja, é retomada a ideia de que os toxicômanos não têm a menor capacidade de decidir sobre si próprios. Eles devem ser periciados e encaminhados à internação, dependendo do grau de dependência atestado (Brasil, 1938, Art. n. 29, $\S 1^{\circ}$ ), uma internação que não poderá ser domiciliar (Brasil, 1938, Art. n. 28) prevista inclusive para usuários de álcool (Brasil, 1938, Art. $n$. 29). Aliás, sendo reconhecido como incapaz de tomar qualquer decisão por conta própria, mesmo em alta, o controle sobre 0 indivíduo volta para a polícia, a qual, segundo o Decreto-Lei n. 891, "deverá ser 
sempre cientificada da concessão de alta ao toxicômano, e, por sua vez, comunicará 0 fato, reservadamente, à autoridade policial competente, para efeito de vigilância" (Brasil, 1938, Art. n. 29, § 10).

Não ocorrerão mudanças significativas nos anos seguintes à promulgação do Decreto-lei n. 891. Somente serão incorporadas, em agosto de 1964 - no início do regime ditatorial - as determinações internacionais acordadas na Convenção Única sobre Entorpecentes, que o Brasil havia participado em 1961, em Nova York (Brasil, 1964). De fato a política de identidade promovida pelo Decreto-Lei 891 de 1938, que distinguia os toxicômanos dos traficantes, somente será transformada pela publicação do Decreto-lei n. 385, de 26 de dezembro de 1968, onde o "PRESIDENTE DA REPÚBLICA, usando da atribuição que Ihe confere $0 \S 1^{\circ}$ do artigo $2^{\circ}$ do Ato Institucional $n^{\circ} 5$, de 13 de dezembro de 1968" (Brasil, 1968), altera o artigo n. 281 do Código Penal de 1940 e subsume à mesma categoria - a de criminoso traficantes e usuários, estabelecendo a mesma sanção para quem traficar e para quem utilizar as drogas ilícitas. Como 0 Decreto-Lei não previa tratamento $\mathrm{e}$ internação para os casos em que os indivíduos fossem diagnosticados como dependentes, estes, por sua vez, não eram obrigados à internação, como antes previa 0 Decreto-Lei 891 de 1938, como é bem observado nas análises de Rodrigues (2004).

Essa alteração na lei mostrou que a política de identidade que reduzia o usuário de drogas à condição de doente era mais forte do que a política de identidade direcionada aos indivíduos que produziam e vendiam as substâncias, pois não ocorreu um aumento na condenação de toxicômanos. Todavia, como facilmente se pode imaginar, ao fracassar na severidade penal pela equiparação legal entre traficantes e usuários, três anos depois esse
Decreto-Lei é revogado, sendo substituído pela Lei n. 5.726, de 29 de outubro de 1971.

A lei de 1971, em relação à de 1968 , torna mais duro 0 artigo n. 281 do Código Penal, aumentando a pena prevista para a produção e 0 tráfico, além de manter 0 inciso III do primeiro parágrafo deste artigo, o qual coloca que a pena também será aplicada a usuários que carregarem consigo qualquer quantidade de drogas, inclusive para uso próprio. Além disso, no caso em que 0 juiz absolver 0 acusado de incorrer no artigo n. 281 do Código Penal, isto é, no caso em que o absolva por não possuir "a capacidade de entender o caráter ilícito" do uso dos psicoativos, este deverá ordenar a internação no hospital psiquiátrico, seguindo - mesmo protocolo de encaminhamento utilizado para tratamento e atenção dos indivíduos com transtornos mentais na época (Lima, 2010a). Como podemos observar, a Lei 5.726 de 1971 não alterou de forma radical o Decreto-lei anterior, uma vez que manteve a equiparação entre usuário e traficante e a opção da cadeia; basicamente a novidade foi a incorporação, nos casos em que houvesse absolvição, da internação compulsória. Ou seja, se antes o acusado só poderia ser internado, e depois só poderia ou ser preso ou solto, agora para ele só haveria duas opções: ou ser preso, ou internado.

Outra alteração importante na construção de uma nova política de identidade estigmatizadora no texto da lei de 1971 será a institucionalização do termo "viciado" para designar os usuários de substâncias psicoativas. O termo "viciado" passa a ser operacional no discurso antidrogas, englobando aqueles que utilizam as substâncias de forma não habitual, não levando em conta, entretanto, os dependentes químicos de drogas lícitas (denominadas remédios) e reforçando um estigma que passa a fazer parte de todos os que chegam a parar de usar os psicoativos: cria-se a imagem dos "ex-viciados", marca a ser carregada pelos que obtiveram alta. 
Ainda no período ditatorial brasileiro, foi promulgada a Lei n. 6.368 , de 21 de outubro de 1976, que no Capítulo II, "Do tratamento e da recuperação", reforça a necessidade do diagnóstico médico (os viciados não deveriam ser encaminhados ao sistema carcerário) para o devido encaminhamento do doente às instituições de saúde e assistência social. A lei passa a determinar que os Estados criem clínicas e ambulatórios para dar contenção aos usuários de drogas, assim como pediam que contratassem pessoal especializado no tratamento desses (Brasil, 1976, art. 9º). A visão de patologia, como vimos, já institucionalizada, recebe mais reforço: "O tratamento sob regime de internação hospitalar será obrigatório quando o quadro clínico do dependente ou a natureza de suas manifestações psicopatológicas assim o exigirem" (Brasil, 1976, art. 10).

Como se verá a seguir, a Lei de drogas de 1976 só será revogada em 2002 após um período de mudanças na esfera pública brasileira. Tais mudanças imprimirão nas novas leis de drogas uma concepção um pouco diferente sobre 0 tratamento do usuário. Contudo, antes de abordarmos a lei de drogas n. 10.409 de 11 de janeiro de 2002 - já revogada - e a lei atualmente em vigor (Lei n. 11.343/2006), vejamos os movimentos que foram contexto de tais mudanças.

As leis de drogas após o regime ditatorial e a possibilidade de superação das políticas de identidade estigmatizadoras

Na década de 1980, o Brasil vive um quadro político e econômico marcado por uma crise no sistema previdenciário e no sistema de assistência à saúde. Tal crise teve ao seu lado 0 fortalecimento dos movimentos oposicionistas à ditadura e a ampliação das discussões por uma assistência à saúde pautada em outro modelo que não exclusivamente 0 privatista (Cunha \& Cunha, 2007). Com a derrota do governo ditatorial nas eleições de 1982 e o início do processo de redemocratização do País, as entidades e as pessoas que defenderam a implantação de novas políticas e novos modelos de organização do sistema, serviços e práticas de saúde, participando de maneira persistente e organizada na esfera política, conseguiram formular e implementar em 1988 o Sistema Único de Saúde (SUS) (Cunha \& Cunha, 2007).

De fato, dois anos antes, em 1986, foi realizada em Brasília a VIII Conferência Nacional de Saúde, que contou com a participação de trabalhadores, membros do governo e usuários dos serviços, cujo documento final propõe um novo enfoque sobre a saúde, a qual deve ser entendida como "resultante das condições de alimentação, habitação, educação, renda, meio ambiente, trabalho, transporte, emprego, lazer, liberdade, acesso e posse da terra e acesso a serviços de saúde" (Cunha \& Cunha, 2007, p. 10).

Nesse mesmo período, esteve em discussão a reforma psiquiátrica no Brasil, que surgiu a partir da defesa dos direitos humanos dos pacientes psiquiátricos, muitas vezes submetidos a contenção física violenta, espancamentos, administração abusiva de sedativos e eletroconvulsoterapia com fins punitivos (e não propriamente terapêuticos). Havia, como vimos anteriormente, uma política de internamento psiquiátrico, que através do serviço privado atendia doentes mentais $\mathrm{e}$ usuários de drogas, em muitos casos submetidos a um regime de isolamento e alienação. Com o movimento da reforma psiquiátrica foram feitas denúncias de violação dos direitos de cidadania de pacientes internados, confirmadas por meio de visitas a tais lugares (Amarante, 1998). Entretanto, foi somente após a participação efetiva dos usuários, familiares, sociedade e técnicos que, enfim, concretizou-se a política de desinstitucionalização psiquiátrica hospitalocêntrica, com a promulgação da Lei 10.216 em 6 de abril 
de2001, mais conhecida como Lei da Reforma Psiquiátrica brasileira1.

Também nesse período, mais especificamente a partir do final dos anos 1980, a Redução de Danos (RD) passa a ser utilizada como forma de prevenir a expansão da epidemia de HIVIAids, principalmente entre os usuários de drogas injetáveis. Diante de toda essa movimentação, o Brasil acabou se tornando o carro chefe da RD na América Latina e em 1998, após a $9^{a}$ Conferência Internacional de Redução de Danos ocorrida em São Paulo, várias associações e redes foram fundadas como forma de garantir a manutenção e ampliação do movimento de Redução de Danos, com propostas estratégicas diferenciadas. Entre as principais associações criadas após a conferência podemos destacar a ABORDA - Associação Brasileira de Redutores de Danos (uma associação de usuários e exusuários de drogas), a RELARD - Rede Latino Americana de RD e a REDUC Rede Brasileira de Redução de Danos (REDUC, s./d.).

Essas instituições foram importantes na medida em que, ao invés de reforçar as políticas de identidade estigmatizadoras que trabalham com a identidade do "criminoso", "viciado" e/ou "doente mental", passaram a fortalecer uma política de identidade de sentido mais emancipatório, prezando a identidade do cidadão, a liberdade e a autonomia do usuário. De fato, é possível dizer que a organização política promovida pelas associações de Redução de Danos possibilitou uma guinada na política de drogas brasileira, que até então relegava para as instituições de justiça, medicina, pedagogia e associações religiosas a responsabilidade frente a essa problemática.

\footnotetext{
1. Para uma melhor compreensão desse período, sobretudo no que se refere às políticas de saúde mental, sugerimos a leitura de: Lima, A. F. (2010a). Metamorfose, anamorfose e reconhecimento perverso \& Lima, A. F. (2010b) Os movimentos progressivos-regressivos da reforma psiquiátrica antimanicomial no Brasil.
}

Podemos dizer ainda que a concepção de Redução de Danos promoveu uma transformação, ainda com grandes críticas e oposições, em relação às concepções que entendiam o tratamento do uso de drogas como sinônimo de abstinência, para uma concepção ampliada de saúde na qual a autonomia do indivíduo serve de referência no tratamento. A Redução de Danos contradiz totalmente a concepção da drogadição como doença crônica (concepção moral-religiosa, moral-científica e nosológica) e se opõe, também, à política repressiva, centrada no lema da "guerra às drogas", bem como opõe-se à chamada "pedagogia do terror", que é aplicada ainda pela maioria das Comunidades Terapêuticas, alguns ambulatórios, hospitais e grupos de ajuda mútua do país.

A importância das organizações e redes que defendiam a implementação da concepção de Redução de Danos também pode ser vislumbrada na III Conferência Nacional de Saúde Mental de 2001, onde foi apresentada a necessidade de se considerar a questão das drogas não apenas sob o ponto de vista do crime ou da patologia. Nessa Conferência, defendeu-se que o Ministério da Saúde deveria garantir a definição de políticas públicas para os usuários de álcool e outras drogas baseadas nos direitos humanos, nos princípios e diretrizes do Sistema Único de Saúde - SUS e da Reforma Psiquiátrica. Destacou-se também a necessidade de "garantir que o SUS se responsabilize pelo atendimento dos usuários de drogas $\mathrm{e}$, ao mesmo tempo, não reduzir essa problemática exclusiva da saúde" (Brasil, 2002a, p. 60).

Esses debates foram vislumbrados, ao menos parcialmente, na Lei n. 10.409 de 11 de janeiro de 2002, que substituiu a Lei $\mathrm{n}$. 6.368/1976. A lei n. 10.409/2002 apresenta uma visão um pouco mais ampla sobre a questão das drogas ao definir como ações preventivas não só a ação policial ostensiva, 
mas o incentivo de "atividades esportivas, artísticas e culturais", "debates de questões ligadas à saúde, cidadania e ética", "serviços de apoio, orientação e supervisão de professores e alunos", "nos hospitais atividades de recuperação de dependentes e de orientação de seus familiares" (Brasil, 2002b, Art. 10, $\S 2^{\circ}$ ). Nesta lei também a concepção de tratamento do usuário muda. Em vez da internação em instituição fechada, passa a reconhecer a Redução de Danos: "Art. 12, $\S 1^{\circ} 0$ tratamento do dependente ou do usuário será feito de forma multiprofissional e, sempre que possível, com a assistência de sua família." e "Art. 12, § $2^{\circ}$ Cabe ao Ministério da Saúde regulamentar as ações que visem à redução dos danos sociais e à saúde" (Brasil, 2002b).

Desde então, o Ministério da Saúde passou a implementar o Programa Nacional de Atenção Integrada aos Usuários de Álcool e outras Drogas, reconhecendo o problema do uso prejudicial de substâncias como um importante problema de saúde pública, "situada no campo da saúde mental, e tendo como estratégia a ampliação do acesso ao tratamento, a compreensão integral e dinâmica do problema, a promoção dos direitos e a abordagem de redução de danos" (Brasil, 2005, p. 46).

Diante da diversidade de tratamentos ao uso de drogas e do entendimento de que, ao se referir às drogas, as formas de tratamento propostas tradicionais têm trazido muito mais problemas para os indivíduos do que possibilidades de autonomia, o Ministério da Saúde propôs em 2003 a Política do Ministério da Saúde para a Atenção Integral a Usuários de Álcool e outras Drogas, na qual a Redução de Danos passa a ser a política pública adotada. A partir de então, a postura preconizada para o profissional de saúde é a de colocar-se na condição de acolhedor, tendo em vista que cada indivíduo traz consigo sua história de vida, expressando sua individualidade e também a de seu contexto de socialização (Brasil, 2003).

Frente a esses avanços na saúde pública, é promulgada a Lei n. 11.343, de 23 de agosto de 2006, que é a lei de drogas atualmente em vigor no Brasil. Esta nova lei, no que tange ao tratamento do usuário de drogas, se mostra mais progressista que as anteriores. Traz explicitamente em seu texto uma consideração para com os direitos humanos, a diversidade cultural existente no país e a autonomia do usuário, sobretudo 0 0 respeito aos direitos fundamentais da pessoa humana, especialmente quanto à sua autonomia, à sua liberdade e o respeito à diversidade $e$ às especificidades populacionais (Brasil, 2006, Art. $4^{\circ}$ ).

Também podemos considerar como avanços da lei atual "a adoção de conceitos objetivos e de fundamentação científica como forma de orientar as ações dos serviços públicos comunitários e privados" - com o objetivo de "evitar preconceitos e estigmatização das pessoas e dos serviços que as atendam", o foco no "fortalecimento da autonomia e da responsabilidade individual em relação ao uso indevido de drogas" (Brasil, 2006, Art. 19), a reiteração do modelo da redução de danos, numa abordagem multidisciplinar (uma das posições consensuais atualmente em saúde pública), visando a reinserção do usuário ou dependente de drogas em redes sociais de apoio e reconhecendo a complexidade do contexto sociocultural em que se insere. $E$, principalmente, a assunção de uma política de identidade que tenha como princípio 0 "respeito ao usuário e ao dependente de drogas, independentemente de quaisquer condições, observados os direitos fundamentais da pessoa humana, os princípios e diretrizes do SUS e da Política Nacional de Assistência Social" e "a adoção de estratégias diferenciadas de atenção e reinserção social do usuário e do dependente de drogas e respectivos familiares que considerem as suas 
peculiaridades socioculturais" (Brasil, 2006, Art.22).

Recentemente, a IV Conferência Nacional de Saúde Mental - Intersetorial (CNSM-I) ocorrida em Brasília, em 2010, que contou com a participação de todos os seguimentos sociais envolvidos direta $\mathrm{e}$ indiretamente com a saúde mental no Brasil, enfatizou que 0 enfrentamento da problemática do uso e abuso de álcool e outras drogas requer "a implantação e 0 desenvolvimento, nos três níveis de atenção, de políticas públicas intersetoriais, em consonância com as diretrizes da reforma psiquiátrica, do Sistema Único de Saúde (SUS), Sistema Único de Assistência Social (SUAS), do Programa Nacional de Direitos Humanos (PNDH) e do Programa de Atenção Integral a Usuários de Álcool e Outras Drogas" (Brasil, 2010).

A IV CNSM-I foi um avanço em relação às conferências anteriores, atendendo assim as exigências reais e concretas, já que desde a III Conferência Nacional de Saúde Mental, de 2001, havia se percebido o aumento na complexidade, multidimensionalidade e pluralidade das necessidades em saúde mental, que concretamente significa a necessidade de instituir, no âmbito dos entes gestores do SUS,

políticas estratégicas e mecanismos para fortalecer a integração da atenção básica com os CAPS; implantar e implementar leitos em hospitais gerais; e de ampliar 0 investimento em projetos de promoção da saúde, prevenção, e de redução de danos, tendo como princípio o respeito às singularidades socioculturais de cada grupo e região e a intersetorialidade cultura, arte, lazer, esporte, educação, emprego e geração de renda (Brasil, 2010, p. 86)

$\mathrm{Na}$ IV CNSM-I (2010), o ponto mais importante discutido e assinalado como um desafio para os próximos anos foi a urgência no investimento, sobretudo utilizando os diferentes meios de comunicação, a divulgação das políticas públicas e as ações do campo da saúde mental, possibilitando a ampliação de conhecimentos da população frente às questões de saúde mental e promovendo a redução dos preconceitos e estigmas associados aos usuários de álcool e outras drogas. Isso não significa que a preocupação com a repressão a produção, tráfico e venda de drogas tenha sido deixada para segundo plano, pelo contrário, foram reforçadas como de extrema importância.

A implementação da Redução de Danos e a promoção de Políticas de Identidade emancipatórias

Acreditamos que com o que foi exposto até agora já seja possível compreender os marcos jurídicos que ajudaram a criar e justificar na esfera pública brasileira as estratégias de repressão às drogas e as políticas de identidade estigmatizadoras direcionadas aos usuários dessas substâncias. Buscamos explorar o contexto histórico de implementação da Redução de Danos enquanto proposta alternativa às políticas de identidade estigmatizadoras. Sabemos que outros aspectos e questões envolvendo a temática abordada não foram exploradas nesse artigo, sobretudo as críticas e limites da política/proposta de redução de danos e o manejo da clínica com os usuários de drogas. Entretanto, devido a complexidade e perigos de uma análise simplista desses temas exploraremos isso em trabalhos futuros.

A guisa de conclusão, pensamos que ainda seja importante tecer mais algumas breves considerações sobre o papel dos psicólogos nesse processo. Afinal, se com a nova proposta de atenção aos usuários de álcool e outras drogas a atenção psicossocial torna-se o eixo principal do processo de reabilitação, é necessário que apresentemos também algumas transformações na forma de tratamento oriundas dessa nova concepção. Quanto a 
isso, tentaremos expor brevemente, a partir do referencial teórico que vem balizando nossos estudos em Psicologia Social (Gonçalves Neto \& Lima, 2010; Lima, 2010a), nossas reflexões acerca do trabalho do psicólogo inserido nessa política.

Levando em conta as questões de identidade envolvidas na problemática, é importante lembrar que para que essas transformações se tornem possíveis é necessário que ampliemos as formas de reconhecimento e os espaços de ação e convivência, pois enquanto a atividade mais relevante do indivíduo for "usar drogas" ou "depender do uso de drogas" e seu reconhecimento for reduzido à condição de "doente em recuperação" a sua identidade será subsumida às categorias "drogado", "viciado", "dependente químico" por mais que no plano discursivo se faça referência à de "cidadão". Afinal, como assinala Galdós (2008, p. 233), essa condição de estigmatizado "não só implica numa representação social negativa do mesmo, com a conseguinte modificação de sua identidade pessoal e social, como também compreende uma série de expectativas sociais de conduta que dificultarão em grande medida sua reinserção social, uma vez superada a independência". Como tal ampliação envolve melhorias sociais, políticas e econômicas a serem conquistadas historicamente, a abordagem da Redução de Danos, pois, é apenas um passo - um passo importante é claro - para um outro reconhecimento do usuário de drogas.

Julgamos imprescindível tanto 0 engajamento político do psicólogo quanto a ampliação da visão clássica acerca dos atuais problemas relacionados ao uso de álcool e outras drogas, que partem das dicotomias: saúde-doença, justiça-delito, religião-pecado etc., para uma perspectiva que assegure a cidadania e 0 reconhecimento de humanidade. Nessa perspectiva também se deve considerar que a dependência de drogas corresponde a um fenômeno que não se confunde apenas com - consumo de drogas, mas sim que corresponde ao encontro de um indivíduo consigo mesmo, com seus valores e crenças; ou seja, "é preciso ver o produto, a droga, inserida na esfera capitalista, num contexto sociocultural, que incentiva, carimba e aprisiona 0 indivíduo na personagem do viciado; é preciso combater as Políticas de Identidade que servem para a manutenção da realidade do indivíduo, impossibilitando muitas vezes que ele consiga sua diferenciação" (Lima, 2005, p. 183), impondo-lhe a heteronomia que nega a experiência e atribui um sentido a priori para sua vida.

Enfim, podemos dizer que antes de se preocupar apenas com a redução do consumo e/ou abstinência dos usuários de drogas, o trabalho do psicólogo deve se condicionar à sua capacidade de ofertar espaços institucionais que possibilitem a alterização dos indivíduos, isto é, criar contextos comunicativos não coercitivos, onde se busca superar expectativas rígidas de comportamento e se incentiva 0 indivíduo a diferenciar-se de padrões tradicionais, vivenciando contextos de interação em que ocorre a coordenação de suas ações com outros parceiros por meio de uma ação comunicativa (Habermas, 2010), encontrando assim possibilidades de autodeterminar-se e autorrealizar-se. Nesse sentido, tal como assinala Márcia Totugui (2009, p. 148), é preciso implicar o usuário em suas escolhas, o que significa, antes de tudo,

(...) ajudá-lo no resgate do direito de exercer sua liberdade, quesito essencial da noção de cidadania, um direito tão tutelado num passado tão presente. Oportunizamos a ele a apropriação de sua condição de cidadão - ou a construção de um saber sobre a mesma -, ao convidá-lo a se implicar, não na renúncia de seu objeto de prazer ou de gozo, e sim num projeto de consumo mais responsável, seguro e consciente. Um projeto que viabilize o exercício de 
sua própria escolha - a continuidade [ou não] de sua relação com a droga -, num nível mais próximo da preservação e proteção de sua saúde. Todavia, tratase, ao mesmo tempo, de convocá-lo a não se despojar de suas responsabilidades sociais e compromisso para com o bem-estar coletivo (Totugui, 2009, p.148).

Portanto, ofertar espaços em que os usuários de drogas possam ter outras experiências significativas de vida além do uso da droga e atribuir outro sentido para 0 uso das substâncias que utiliza/utilizava, enfim, abrir a possibilidade de fazer outras escolhas até então nem mesmo pensadas.

\section{REFERENCIAS}

Amaral, I. S. (2000). A sociedade de consumo e a produção da toxicomania. Dissertação de Mestrado em Psicologia Social, Pontifícia Universidade Católica de São Paulo, São Paulo, SP, Brasil.

Amarante, P. (1998). Loucos pela vida: a trajetória da reforma psiquiátrica no Brasil. Rio de Janeiro: Fiocruz Editora.

Amarante, P. (2007). Saúde Mental e Atenção Psicossocial. Rio de Janeiro: Fiocruz Editora.

Brasil. (1824). Constituição Política do Império do Brazil de 25 de março de 1824. Rio de Janeiro. 1824. Recuperado em 2 junho, 2011,

de http://www.planalto.gov.br/ccivil_03/constit uicao/constitui\%C3\%A7ao24.htm.

Brasil. (1851). Decreto n. 828, de 29 de setembro de 1851. Manda executar 0 Regulamento da Junta de Hygiene Publica. In Collecção das Leis do Império do Brasil de 1851, tomo XIV, parte II, pp. 259-275. Rio de Janeiro: Typographia Nacional. Recuperado em 2 junho, 2011, de http://www.camara.gov.br/Internet//nfDoc/c onteudo/colecoes/Legislacao/Legimp-

39_29.pdf e de http://www.camara.gov.br/Internet//nfDoc/c onteudo/colecoes/Legislacao/Legimp39_30.pdf.

Brasil. (1921). Decreto n. 4.294 de 6 de julho de 1921. Estabelece penalidades para os contraventores na venda de cocaina, ópio, morphina e seus derivados; crêa um estabelecimento especial para internação dos intoxicados pelo alcool ou substancias venenosas; estabelece as fórmas de processo e julgamento e manda abrir os creditos necessarios. In Colecção das Leis da República dos Estados Unidos do Brasil de 1921, vol. 1, Actos do Poder Legislativo, janeiro a dezembro. Rio de Janeiro: Imprensa Nacional. pp. 273-275. Recuperado em 2 junho, 2011, de http://www.camara.gov.br/internet//nfDoc/n ovoconteudo/legislacao/republica/Leis1921 v1-674p/pdf30.pdf. e de http://www.camara.gov.br/internet//nfDoc/n ovoconteudo/legislacao/republica/Leis1921 v1-674p/pdf31.pdf.

Brasil. (1921). Decreto n. 14.969 de 3 de setembro de 1921. Approva o regulamento para a entrada no paiz das substancias toxicas, penalidades impostas aos contraventores e sanatorio para toxicomanos. In Colecção das Leis da Republica dos Estados Unidos do Brasil de 1921, vol. 5, Actos do Poder Executivo, setembro a novembro. Rio de Janeiro: Imprensa Nacional. pp. 7-14. Recuperado em 2 junho, 2011, de http://www.camara.gov.br/internet//nfDoc/n ovoconteudo/legislacao/republica/leis1921 v5-512p/pdf-04.pdf. e de http://www.camara.gov.br/internet/InfDoc/n ovoconteudo/legislacao/republica/leis 1921 v5-512p/pdf-04-a.pdf.

Brasil. (1923a). Decreto n. 4.665 de 24 de janeiro de 1923. Considera de utilidade publica a Liga Nacional contra 0 Alcoolismo e outras instituições. In Colecção das Leis dos Estados Unidos do Brasil de 1923, vol. 1, Actos do Poder Legislativo, janeiro a dezembro. Rio de Janeiro: Imprensa Nacional. p. 112. Recuperado em 2 junho, 2011, de http://www.camara.gov.br/Internet/InfDoc/n ovoconteudo/Legislacao/Republica/leis 192 3v1-290pag/pdf-14a.pdf.

Brasil. (1923b). Decreto n. 4.778 de 27 de dezembro de 1923. Considera de utilidade publica a Liga Brasileira de Hygiene Mental, com séde nesta Capital. In Colecção das Leis dos Estados Unidos do Brasil de 1923, vol. 1, Actos do Poder Legislativo, janeiro a dezembro. Rio de Janeiro: Imprensa Nacional. p. 197. Recuperado em 2 junho, 2011, de 
http://www.camara.gov.br/Internet/InfDoc/n ovoconteudo/Legislacao/Republica/leis192 3v1-290pag/pdf-23.pdf.

Brasil. (1934). Decreto n. 24.559 de 3 de julho de 1934. Dispõe sôbre a profilaxia mental, a assistência e proteção á pessôa e aos bens dos psicopatas, a fiscalização dos serviços psiquiátricos e dá outras providências. Rio de Janeiro. Recuperado em 2 junho, 2011, de http://www6.senado.gov.br/legislacao/Lista TextoIntegral. action?id=20366.

Brasil. (1936). Decreto $n .780$ de 28 de abril de 1936. Crêa a commissão permanente de fiscalização de entorpecentes. Diário Oficial, Poder Executivo, Rio de Janeiro. Recuperado em 2 junho, 2011, de http://www6.senado.gov.br/legislacao/Lista Normas.action?numero=780\&tipo_norma= DEC\&data $=19360428 \&$ link $=s$.

Brasil. (1938). Decreto-Lei n. 891, de 25 de novembro de 1938. Aprova a Lei de Fiscalização de Entorpecentes. Coleção das Leis do Brail, Poder Executivo, Rio de Janeiro. Recuperado em 2 junho, 2011, de http://www.planalto.gov.br/ccivil/DecretoLei/1937-1946/Del0891.htm.

Brasil. (1964). Decreto n. 54.216 de 27 de agosto de 1964. Promulga a Convenção Única sôbre Entorpecentes. Diário Oficial, Poder Executivo, Brasília. Recuperado em 2 junho 2011, de http://www6.senado.gov.br/legislacao/Lista Normas .action? numero $=54216 \&$ tipo_norm $a=D E C \& d a t a=19640827 \&$ link $=s$.

Brasil. (1968). Decreto-Lei $n^{\circ} 385$, de 26 de dezembro de 1968. Dá nova redação ao artigo 281 do Código Penal. Diário Oficial da União, Poder Executivo, Brasília, DF. Recuperado em 2 junho, 2011, de https://www.planalto.gov.br/ccivil_03/decret o-lei/1965-1988/Del0385.htm.

Brasil. (1971). Lei n. 5.726, de 29 de outubro de 1971. Dispõe sobre medidas preventivas e repressivas ao tráfico e uso de substâncias entorpecentes ou que determinem dependência física ou psíquica e dá outras providências. Diário Oficial da União, Poder Executivo, Brasília. Recuperado em 2 junho, 2011, de https://www.planalto.gov.br/ccivil_03/Leis/1 970-1979/L5726.htm.

Brasil. (1976). Lei n. 6.368, de 21 de outubro de 1976. Dispõe sobre medidas de prevenção e repressão ao tráfico ilícito e uso indevido de substâncias entorpecentes ou que determinem dependência física ou psíquica, e dá outras providências. Diário Oficial da União, Poder Executivo, Brasília. Recuperado em 2 junho, 2011, de https://www.planalto.gov.br/ccivil_03/leis/l6 368.htm.

Brasil. (2001). Lei n. 10.216, de 6 de abril de 2001. Dispõe sobre a proteção e os direitos das pessoas portadoras de transtornos mentais e redireciona o modelo assistencial em saúde mental. Diário Oficial da União, Poder Executivo, Brasília. Recuperado em 2 junho, 2011, de https://www.planalto.gov.br/ccivil_03/leis/lei s_2001//10216.htm.

Brasil. (2002a). Relatório Final da III Conferência Nacional de Saúde Mental. Brasília:

Ministério da Saúde, Conselho Nacional de Saúde.

Brasil. (2002b). Lei n. 10.409, de 11 de janeiro de 2002. Dispõe sobre a prevenção, 0 tratamento, a fiscalização, o controle e a repressão à produção, ao uso e ao tráfico ilícitos de produtos, substâncias ou drogas ilícitas que causem dependência física ou psíquica, assim elencados pelo Ministério da Saúde, e dá outras providências. Diário Oficial da União, Poder Executivo, Brasília. Recuperado em 2 junho, 2011, de https://www.planalto.gov.br/ccivil_03/leis/2 002/10409.htm.

Brasil. (2010). Relatório Final da IV Conferência Nacional de Saúde Mental. Brasília:

Ministério da Saúde, Conselho Nacional de Saúde.

Brasil. (2003). Ministério da Saúde. Secretaria Executiva. Secretaria de Atenção a Saúde. Coordenação Nacional DST/AIDS. A Política do Ministério da Saúde para Atenção Integral a Usuários de Álcool e Outras Drogas. Brasília: Ministério da Saúde.

Brasil. (2005). Reforma psiquiátrica e política de saúde mental no Brasil. Documento apresentado à Conferência Regional de Reforma dos Serviços de Saúde Mental: 15 anos depois de Caracas. Brasília: OPAS.

Brasil. (2004). Álcool e redução de danos: uma abordagem inovadora para países em transição. Brasilia: Ministério da Saúde.

Brasil. (2006). Lei no 11.343, de 23 de agosto de 2006. Institui o Sistema Nacional de 
Políticas Públicas sobre Drogas - Sisnad; prescreve medidas para prevenção do uso indevido, atenção e reinserção social de usuários e dependentes de drogas; estabelece normas para repressão à produção não autorizada e ao tráfico ilícito de drogas; define crimes e dá outras providências. Diário Oficial da União, Poder Executivo, Brasília. Recuperado em 2 junho, 2011, de https://www.planalto.gov.br/ccivil_03/_Ato2 004-2006/2006/Lei/L11343.htm.

Cunha, J. P. P. \& Cunha, R. E. (2007). Sistema Único de Saúde - SUS: Princípios. In N. M. N. Moyses (Org.). Políticas Públicas e Gestão do Trabalho em Saúde. [Apostila Unidade I do Curso de Especialização em Gestão do Trabalho e da Educação em Saúde]. Rio de Janeiro: FIOCRUZ.

Escohotado, A. (1997). A proibição: princípios e conseqüências. In M. M. Ribeiro \& S. D. Seibel (Org.). Drogas: a hegemonia do cinismo (pp. 29-46). São Paulo: Memorial.

Foucault, M. (2009). A verdade e as formas jurídicas. Rio de Janeiro: NAU Editora.

Foucault. M. (1999). Os Anormais. São Paulo: Martins Fontes.

Galdóz, J. S. (2008). El estigma del drogadicto. In R. G. Fernández (Org.). Psicosociología del estigma: ensayos sobre la diferencia, el prejuicio y la discriminación (pp. 211-240). Madrid: Universitas.

Galeano, E. (1998). Patas arriba: La escuela del mundo al revés. Madrid: Siglo Veintiuno de España Editores.

Goffman, E. (1988). Estigma: Notas sobre a Manipulação da Identidade Deteriorada. Rio de janeiro: Zahar.

Gonçalves Neto, J. U. \& Lima, A. F. (2010). Reconhecimento social, identidade e linguagem: primeiros fragmentos de uma pesquisa sobre perspectivas teóricas atuais no contexto da Psicologia Social. In Revista Psicologia e Saúde, 2(1), 90-97. Recuperado em 5 fevereiro, 2011, de http://www.gpec.ucdb.br/pssa/index.php/ps sa/article/view/40.

Habermas, J. (2010). Fundamentação Linguística da Sociologia: Obras Escolhidas (Vol. 1). Lisboa: Edições 70.

Lima, A. F. (2005). A dependência de drogas como um problema de Identidade: Possibilidades de apresentação do EU por meio da oficina-terapêutica de teatro. Dissertação de Mestrado em Psicologia,
Pontifícia Universidade Católica de São Paulo, São Paulo, SP, Brasil.

Lima, A. F. (2010a). Metamorfose, Anamorfose e Reconhecimento Perverso: a identidade na perspectiva da psicologia social crítica. São Paulo: FAPESP; Educ.

Lima, A. F. (2010b). Os movimentos progressivos-regressivos da reforma psiquiátrica antimanicomial no Brasil: uma análise da saúde mental na perspectiva da Psicologia Social Crítica. In Revista Salud \& Sociedad, Chile, 1(3), 165-177. Recuperado em 5 fevereiro, 2011, de www.saludysociedad.cl/index.php/main/arti cle/download/24/50.

Macrae, E. (2008). Aspectos Socioculturais do Uso de Drogas e Políticas de Redução de Danos. Recuperado em 10 novembro, 2010,

de http://www.neip.info/downloads/edward2.p df.

Rede Brasileira de Redução de Danos REDUC. (sem data). Rede +: Cartilha da Reduc de Redução de Danos. Fascículo 2. São Paulo: REDUC.

Rodrigues, T. (2003). Política de Drogas e a Lógica dos Danos. In Revista Verve, São Paulo, Nu-Sol/PUC-SP, 3(1), 257277. Recuperado em 7 novembro, 2010, de www.neip.info/downloads/t_tia3.pdf.

Rodrigues, T. (2004). Política e drogas nas Américas. São Paulo: Educ.

São Paulo. (1911). Decreto estadual $n^{\circ} 2.141$, de 04 de novembro de 1911. Reorganiza o Serviço Sanitario do Estado. São Paulo, Brasil. Secretaria de Estado dos Negocios do Interior. Recuperado em 2 junho, 2011, de

http://www.al.sp.gov.br/repositorio/legislaca o/decreto/1911/decreto\%20n.2.141,\%20de \%2014.11.1911.htm.

Totugui, M. L. (2009). Possibilidades integradoras da redução de danos na perspectiva da complexidade - estudo teórico clínico no contexto da psicoterapia de dependentes de drogas. Dissertação de Mestrado em Psicologia Clínica e Cultura, Universidade de Brasília, Brasília, DF, Brasil.

Velho, G. (1997). Drogas, Níveis de Realidade e Diversidade Cultural. In M. M. Ribeiro \& S. D. Seibel (Org.). Drogas: a hegemonia do cinismo (pp. 71-89). São Paulo: Memorial. 